\title{
Autonomic Modulation of the Heart in Systemic Arterial Hypertension
}

\author{
José Barbosa Filho, Paulo Roberto B. Barbosa, Ivan Cordovil \\ Rio de Janeiro, RJ - Brazil
}

\begin{abstract}
Objective - To analyze the heart rate variability in patients with mild to moderate systemic arterial hypertension.

Methods - Thirty-two healthy (group I) and 70 systemic arterial hypertensive (group II) individuals, divided according to age (40 to 59 and 60 to 80 years old, respectively) and with a similar distribution by sex were studied. Thirty-one had left ventricular hypertrophy (LVH), 22 were overweight, and 16 had Type II diabetes mellitus. Smoking, alcohol ingestion, and sedentary habits were the same between groups. Variability in heart rate was analyzed in the time domain, using standard deviations of normal $R R$ intervals (SDNN) and the differences between maximal bra$d y$-and tachycardia $\left(D-B T_{\text {max }}\right)$ during sustained inspiration. Analysis of the frequency band of the power spectrum between 0.05 and $0.40 \mathrm{~Hz}$ at rest and during controlled respiration was chosen for analysis of the frequency domain.
\end{abstract}

Results - In both time and frequency domains, variables were lower in group II than in group I. Within groups, statistically significant variables were only found for individuals in the 40 to 59 year old group. The presence of $L V H$, overweight, or diabetes mellitus did not influence the variability in heart rate to a significant extent.

Conclusion - Variability in heart rate was a valuable instrument for analyzing autonomic modulation of the heart in arterial hypertension. The autonomic system undergoes significant losses in cardio-modulatory capacity, more evident in subjects between 40 and 59 years old. In those over 60 years old, reduced variability in heart rate imposed by aging was not significantly influenced by the presence of systemic arterial hypertension.

Key words: autonomic cardiac modulation, systemic arterial hypertension, heart rate variability

Instituto Nacional de Cardiologia Laranjeiras, Ministério da Saúde e Universidade Gama Filho

Mailing Address: José Barbosa Filho - Rua Sousa Lima, 32/201 - 22081-010, Rio de Janeiro, RJ - Brazil - E-mail: jbmfilh@attglobal.net
Clinical and experimental studies have demonstrated that the autonomic modulator capacity of the cardiovascular apparatus is altered in diseases directly or indirectly affecting the heart ${ }^{1-9}$. In diseases accompanied by alterations in the vagosympathetic system leading to the development of potentially fatal arrhythmia, both morbidity and mortality are significantly influenced by such functional alterations ${ }^{10-18}$.

Interest in the evaluation of autonomic modulation of the heart by analysis of beat-for-beat variability in heart rate in systemic arterial hypertension (SAH) has been variously demonstrated. Results have proven that this variability can identify alterations in the mechanism of autonomic control of SAH, also aiding in the evaluation of the action of drugs that interfere with the regulation of cardiovascular function ${ }^{9,19-27}$.

The present work represents a study of the autonomic modulation of the heart, using the analysis of the variability in heart rate of selected groups of healthy and primary arterial hypertensive subjects.

\section{Methods}

The study protocol was set up in accordance with the principles of the Helsinki Declaration and authorized by the Ethics Commission of the National Institute of Cardiology of Laranjeiras (INCL).

The study was transversally performed in 102 subjects admitted for initial evaluation at the outpatient clinic of the Division of Arterial Hypertension of the Institute-between January 1998 and July 2000. Subjects were between 40 and 80 years old and were divided in two groups paired by age and sex. Group I was composed of 32 healthy individuals; group II was composed of 70 subjects having mild to moderate hypertension defined by a systolic arterial pressure of $\geq 140 \mathrm{mmHg}$ and $\leq 180 \mathrm{mmHg}$, and a diastolic arterial pressure of $\geq 90 \mathrm{mmHg}$ and $\leq 110 \mathrm{mmHg}$. Of group II, $72 \%$ of the subjects were under no treatment, and $28 \%$ made irregular use of thiazide drugs, dihydropyridine calcium channel antagonists, and angiotensin-converting enzyme inhibitors. All were in sinus rhythm (Table I). 


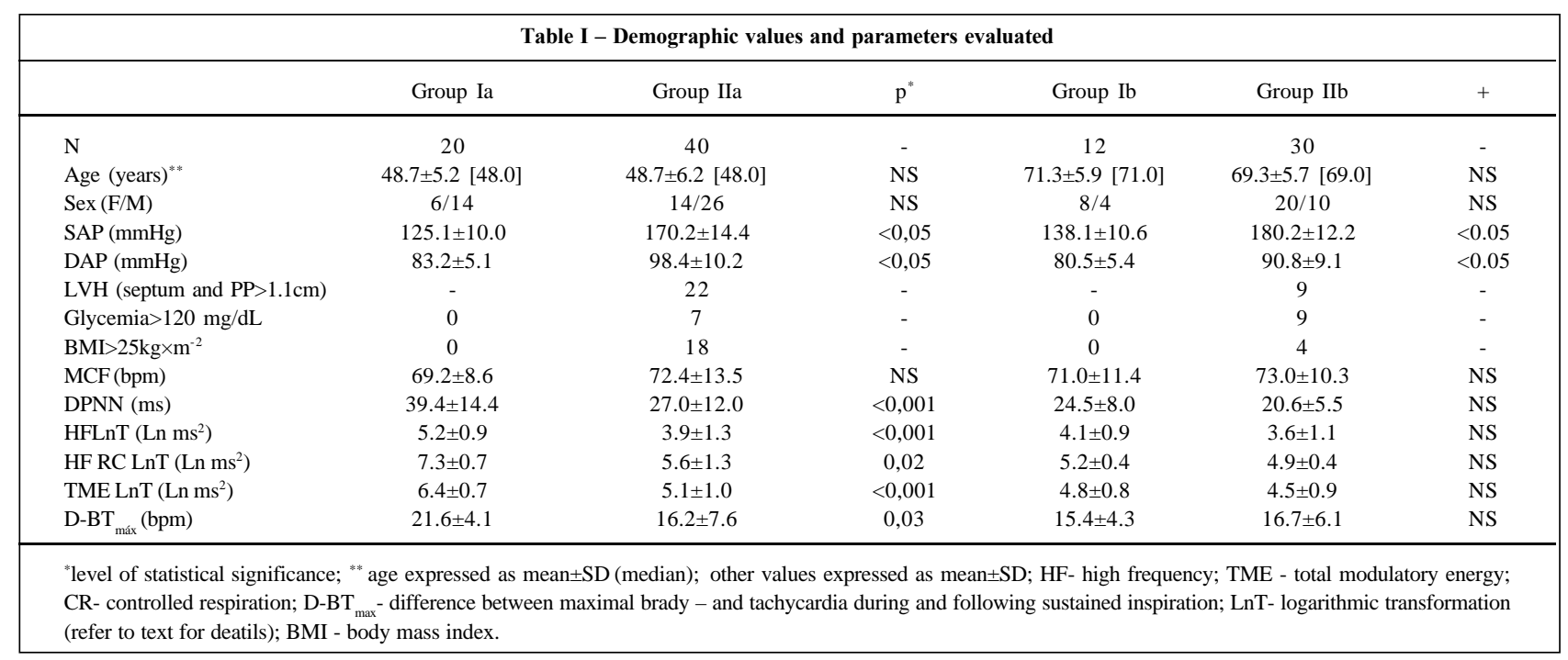

Twenty group I individuals were between 40 and 59 years old (mean $\pm \mathrm{SD}, 48.7 \pm 5.2$; median 48 years) (group Ia, 14 males), and 12 were between 60 and 80 years old $(71.3 \pm 5.9$, median 71 years) (group Ib, 8 males). Their clinical histories, results of the physical examination, laboratory and radiological examinations, and electrocardiograms (ECG) at rest were within normal limits.

In group II, 40 subjects were between 40 and 60 years old (48.7 \pm 6.2 , median 48 years) (group IIa, 26 males), and 30 were between 60 and 80 years old $(69.3 \pm 5.7$, median 69 years) (group IIb, 10 males) (Table I). Thirty-one had left ventricular hypertrophy $(\mathrm{LVH})$ on the echocardiogram at rest, defined by septal and left ventricle posterior wall thickness $>1.1 \mathrm{~cm}$ according to the routine protocol of analysis of the echocardiography sector of the INCL. Twenty-two were overweight defined by a body mass index $\geq 25 \mathrm{~kg} / \mathrm{m}^{-2}$. Sixteen had noninsulin dependent diabetes mellitus of Type II and maintained glycemic control with diet or oral hypoglycemic therapy or both. Smoking habits, alcohol ingestion, and sedentary lifestyle were not different among the groups.

Criteria for inclusion in the study are presented in Table II.
Clinical evaluation included measurements of heart rate, arterial pressure on both arms, antero-posterior thoracic diameter, body weight and height, and body mass index. Anamnesis was directed at the investigation of clinical complaints and physical examination, and complementary examinations including glycemia, cholesterolemia, assessment of renal and liver function, ECG at rest, and thoracic roentgenogram were within normal limits. The Romhilt-Estes index was used for the electrocardiographic diagnosis of LVH. Electrocardiographic signals were used for the analysis of the variability of heart rate as described below. Medical attention and examinations were performed between $8 \mathrm{AM}$ and 6PM.

Following a 5 to 10 minutes rest period in the dorsal decubitus position, arterial pressure was measured on both arms of subjects seated in a quiet room at $25^{\circ} \mathrm{C}$. Arterial pressure was measured after 1,3 , and 5 minutes, and averages of the last 2 measurements were recorded. The arm showing the highest arterial pressure values was taken as standard. Mercury column sphygmomanometers calibrated by INMETRO (National Institute of Metrology) were used.

Electrocardiographic signals on an AECG03, (Lynx Technology, São Paulo, Brazil) were recorded for 300 seconds

\begin{tabular}{|c|c|c|c|}
\hline \multicolumn{4}{|c|}{ Table II - Criteria for inclusion and exclusion in study groups } \\
\hline \multicolumn{2}{|c|}{ Group I } & \multicolumn{2}{|c|}{ Group II } \\
\hline $\begin{array}{l}\text { Criteria for inclusion } \\
\text { Age } \geq 40 \text { and } \leq 80 \text { years } \\
\text { DAP }<90 \mathrm{mmHg} \\
\text { SAP }<140 \mathrm{mmHg}\end{array}$ & $\begin{array}{c}\text { Criteria for exclusion } \\
\text { Non-sinus rhythm } \\
\text { Psychiatric or neurologic } \\
\text { disease } \\
\text { AMI or ACD*** } \\
\text { Pregnancy } \\
\text { Thyroid, renal or } \\
\text { hepatic dysfunction } \\
\text { CTI } \geq 50 \% \\
\text { Diabetes mellitus }\end{array}$ & $\begin{array}{l}\text { Criteria for inclusion } \\
\text { Age } \geq 40 \text { and } \leq 80 \text { years } \\
90 \leq \mathrm{DAP} \leq 110 \mathrm{mmHg} \\
140 \leq \mathrm{SAP} \leq 180 \mathrm{mmHg}\end{array}$ & $\begin{array}{c}\text { Criteria for exclusion } \\
\text { Non-sinus rhythm } \\
\text { Psychiatric or neurologic } \\
\text { disease } \\
\text { AMI or ACD } \\
\text { CTI } \geq 50 \% \text { or EF }<45 \% \\
\text { Thyroid, renal or } \\
\text { hepatic dysfunction } \\
\text { Use of b-blocker } \\
\text { COPD } \\
\text { Secondary HAS }\end{array}$ \\
\hline
\end{tabular}

"DAP- diastolic arterial pressure; ${ }^{* *}$ SAP- systolic arterial pressure; ${ }^{* * *}$ ACD- previous arterial coronary disease; AMI- previous acute myocardial infarct; CTIcardio-thoracic index; EF- left ventricular ejection fraction on echocardiogram at rest; COPD- chronic obstructive pulmonary disease. 
and analyzed by theSAECG system as already described ${ }^{6,7,28}$. Signals were taken between $10 \mathrm{AM}$ and 6PM from subjects kept in the dorsal decubitus position, breathing with theirnatural frequency in an isolated room at $25^{\circ} \mathrm{C}$ at least 2 hours following their meals. In smokers, measurements were taken at least 30 minutes after ending tobacco intake.

Additional ECGs of 60 seconds duration each were recorded from subjects randomly selected from each experimental group, ( 6 from groups Ia and IIa, 4 from groups IIa and IIb) who kept under respiratory control at a respiratory frequency of 12 incursions $/ \min 0.20 \mathrm{~Hz}$, monitored by the examiner with timing equipment. For a second record, 20 individuals from group I ( 12 from group Ia and 8 from group 1b) and 35 from group II ( 15 from group IIa, 20 from group IIb) had their ECGs taken during a sustained inspiration maneuver ${ }^{7}$, composed of 3 phases of respectively, 15, 15, and 30 seconds duration. During the first phase, subjects were instructed to breathe spontaneously; during the second phase, of sustentation, they were required to exert apnea following maximal inspiration without expiratory effort, a procedure differing therefore from the Valsalva maneuver. During this phase, an initial rise of 2 to 3 seconds in average values of heart rate was observed was followed by 8 to 10 seconds of intense bradycardia followed in turn by a progressive increase in heart rate. After a 15-second interval, the subjects were instructed to release their inspired air and to return to spontaneous respiration. At this point ( $3^{\text {rd }}$ phase), heart rate increased to values above averages observed during the first phase and gradually returned to base levels, a typical response of 5 to 10 seconds duration (Figure 1). Records were taken sequentially from subjects remaining in the dorsal decubitus position between readings.

Two domains were analyzed: in the frequency domain, a series of normal consecutive RR intervals was interpolated and the power spectrum calculated using a previously described technique ${ }^{28}$. The area under the spectrum in the region between $0.05 \mathrm{~Hz}$ and $0.40 \mathrm{~Hz}$ corresponding to sympathetic and parasympathetic energy modulation was calculated. The region analyzed is classically decomposed into two frequency bands: one, of low frequency between 0.05 and $0.15 \mathrm{~Hz}$, corresponds to predominantly sympathe-

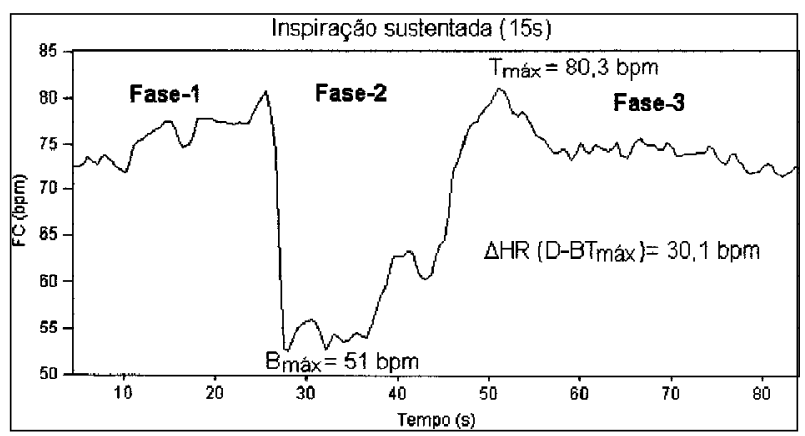

Fig. 1 - Effects of sustained inspiration (SI) on a series of RR intervals in an individual in group I. Note the different phases of the maneuver and the characteristics of Phase 2 that portray the oscillation consequent to sustained inspiration, and the points of analysis and of maximal bradycardia $\left(\mathrm{B}_{\max }\right)$ and tachycardia $\left(\mathrm{T}_{\max }\right)$. Phase 1 , pre-SI; phase 2, SI; phase 3, post-SI. tic influences; the other, of high frequency between 0.15 and $0.40 \mathrm{~Hz}$, corresponds to parasympathetic influences on the variability of heart rate. Due to the marked superpositioning of sympathovagal influences at the frontier region of $0.15 \mathrm{~Hz}$, the entire total energy modulation region was chosen for analysis. During the controlled respiration maneuver, practically all the energy of the spectrum was concentrated in the high frequency region, indicating a predominance of vagal activity. The difference between this energy and that obtained during rest periods was considered to represent the autonomic reserve of modulation of the variability of heart rate (Figure 2).

To analyze the time domain, averaged heart rate or means of the 60/RR ( $R R=R R$ interval in seconds) relationships and the standard deviations (SDNN) of all normal consecutive intervals were considered. The differences between values of maximal bradycardia during and of maximal tachycardia immediately following the phase of sustained inspiration were taken as indexes of autonomic activity (D-BT ${ }_{\text {max }}$ ) corresponding to the modulator potential of the autonomic nervous system.

Body mass index was calculated with the formula BMI=weight $(\mathrm{kg}) \times$ height $^{2}\left(\mathrm{~m}^{-2}\right)$.

Continuous variables were represented in terms of averages \pm standard deviation. Due to the strong asymmetry of its probability distribution function, for normalization prior to analysis, the variables of total energy modulation were transformed into natural logarithms (LnT).

A comparison between the variations in groups I and II in the frequency and time domains were made using Student's two-tailed $t$ test. Discrete variables were analyzed by the chi-square test using Yates correction or Fisher's exact test, for small samples.

The influence of controlled respiration on the high frequency region of the power spectrum was compared with that of the rest period for each group, using Student's twotailed paired $t$ test. Differences between high frequency LnT values at controlled respiration and at rest were compared with this test using unpaired approach.

Individuals in each age of group II were stratified regarding the presence of $\mathrm{LVH}$, overweight, and diabetes and analyzed; a two-tailed Student's $t$ test was used to compare their variables in the frequency and time domains.

For analysis of their diagnostic values, variables in the frequency and time domains-were dichotomized as belonging to groups of subjects aged between 40 and 59 years and above 60 years old, respectively. This was achieved by analyzing the function defined by the products of the distributions of the probability functions of each group (see Appendix). Specificity and sensitivity values were identified at points maximizing this function; their statistical significance was evaluated by the application of the chi-square test to the comparisons of proportions. Data were analyzed using the statistical modulus Stratographics (Statistical Graphics Corporation, USA). Global significance levels were set at 0.05 for all tests. 


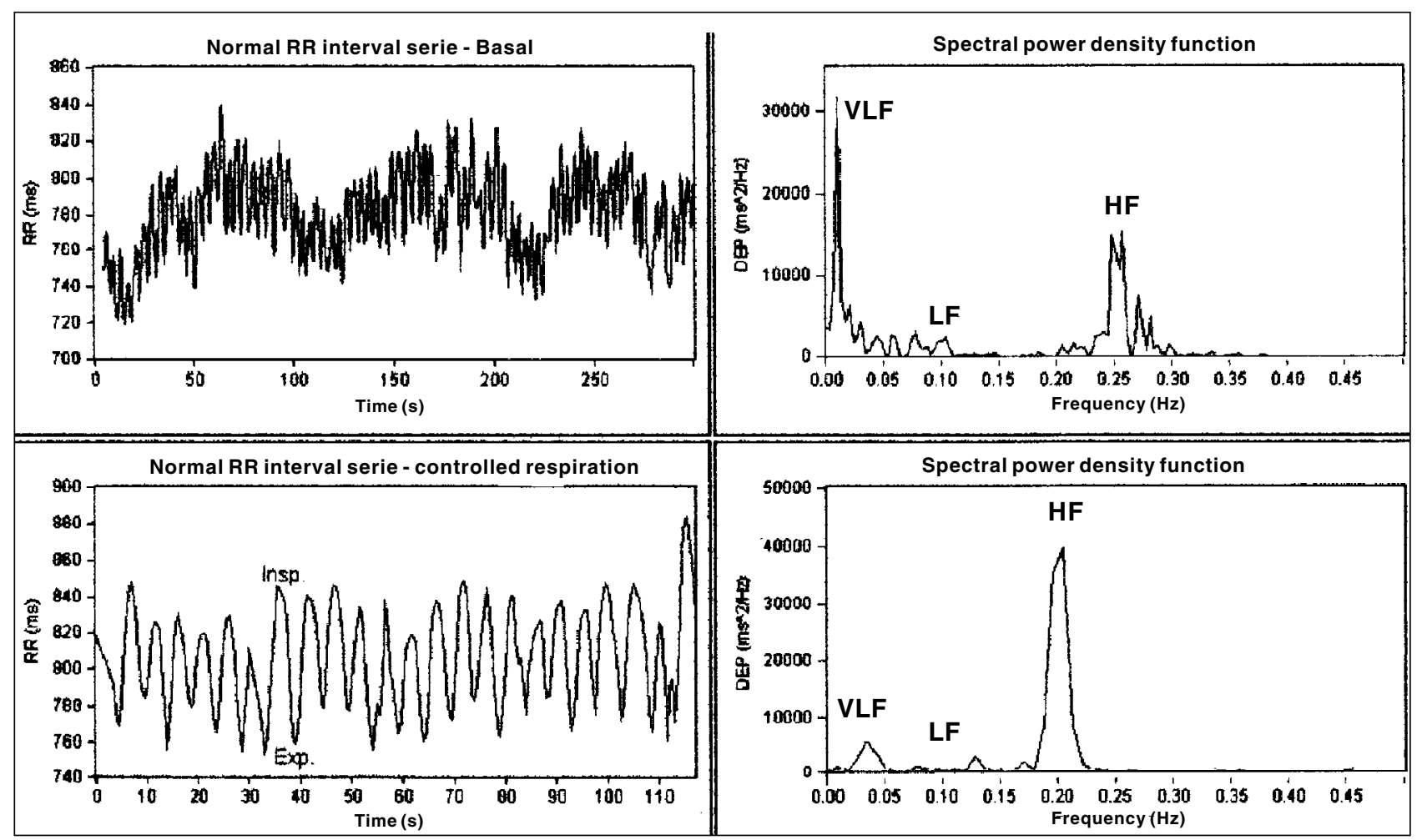

Fig. 2 - Effect of controlled respiration (CR) on the power spectrum of subjects in group I. To the left, a series of normal RR intervals; to the right, the respective power spectrum in a basal record (above) and during the CR maneuver (below). Note that during CR, the energy of the spectrum is concentrated in the high frequency band and its value is significantly increased. VLF, very low frequency (0.01-0.05 HZ); LF, low frequency (0.05-0.15 Hz); HF, high frequency (0.15-0.40 Hz); insp - inspiration; exp - expiration.

\section{Results}

Table I presents modulation energy values logarithmically transformed of groups studied in the frequency domain. Values for group Ila were significantly $(\mathrm{p}<0.001)$ lower than those for group Ia. Differences between values for groups IIb and group Ib were not significant. LnT rises at high frequency (HF) during controlled respiration (CR) in group IIa were lower than those in group Ia $(\mathrm{p}=0.02)$. LnTs in group IIb were not different from those in group Ib ( $>0.05)$.

Values of SDNN and of D-BT ${ }_{\max }$ in the time domain of group IIa were smaller than those in group Ia $(\mathrm{p}<0.001$, and $\mathrm{p}=0.03$. respectively). Records for group IIb were not different from those for group Ib (Table I).

The presence of LVH, overweight, or diabetes did not significantly influence the variability in heart rate in groups II a and IIb (Tables III and IV). Differences were recorded for HFCR and left ventricular hypertrophy for group IIa.

Table V shows frequency and time domains variables sectioned according to age (for groups I and II). Between 40 and 59 years old, values after sectioning equal $74.1 \%$ specificity at high frequency $(\mathrm{p}<0.001)$ and $100 \%$ specificity at high frequency during controlled

Table III - Comparison between VRR parameters of group IIa patients with and without left ventricle hypertrophy (LVH), type II diabetes mellitus (DM), and overweight (OW)

\begin{tabular}{|c|c|c|c|c|c|c|c|c|c|}
\hline & LVH & No-LVH & $\mathrm{p}^{*}$ & DM & No-DM & $\mathrm{p}^{*}$ & OW & No-OW & $\mathrm{p}^{*}$ \\
\hline $\mathrm{N}$ & 22 & 18 & - & 7 & 33 & - & 18 & 22 & - \\
\hline Age (years) & $47.8 \pm 5.5$ & $49.8 \pm 6.7$ & NS & $54.9 \pm 5.7$ & $47.4 \pm 4.4$ & 0.003 & $48.2 \pm 5.5$ & $48.9 \pm 7.2$ & NS \\
\hline $\operatorname{Sex}(F / M)$ & $9 / 13$ & $5 / 13$ & NS & $2 / 5$ & $12 / 21$ & NS & 7/11 & $7 / 15$ & NS \\
\hline $\mathrm{MCF}(\mathrm{bpm})$ & $72.7 \pm 14.0$ & $72.1 \pm 13.2$ & NS & $73.0 \pm 8.0$ & $72.3 \pm 14.5$ & NS & $73.1 \pm 12.3$ & $71.2 \pm 12.1$ & NS \\
\hline DPNN (ms) & $27.4 \pm 11.2$ & $26.5 \pm 13.3$ & NS & $26.1 \pm 5.8$ & $27.2 \pm 13.0$ & NS & $28.1 \pm 13.4$ & $27.3 \pm 10.6$ & NS \\
\hline TME LnT $\left(\operatorname{Ln~ms}{ }^{2}\right)$ & $5.2 \pm 1.0$ & $5.0 \pm 1.0$ & NS & $5.0 \pm 0.4$ & $5.1 \pm 1.1$ & NS & $5.2 \pm 0.9$ & $5.1 \pm 0.9$ & NS \\
\hline $\mathrm{HF} \operatorname{LnT}\left(\operatorname{Ln} \mathrm{ms}^{2}\right)$ & $4.0 \pm 1.4$ & $3.9 \pm 1.3$ & NS & $3.7 \pm 0.8$ & $4.0 \pm 1.4$ & NS & $4.1 \pm 1.2$ & $3.9 \pm 1.2$ & NS \\
\hline HF CR LnT (Ln ms²) & $4.1 \pm 0.7$ & $6.3 \pm 0.7$ & 0.01 & $5.1 \pm 1.3$ & $6.5 \pm 0.7$ & NS & $6.0 \pm 1.1$ & $4.9 \pm 1.8$ & NS \\
\hline $\mathrm{D}-\mathrm{BT}_{\text {máx }}(\mathrm{bpm})$ & $14.9 \pm 3.8$ & $17.0 \pm 9.5$ & NS & $16.4 \pm 8.7$ & $16.0 \pm 7.0$ & NS & $15.0 \pm 7.6$ & $19.2 \pm 7.2$ & NS \\
\hline
\end{tabular}

*- Level of statistical significance; values expressed as mean $\pm \mathrm{SD}$; HF- high frequency; TME LnT- total modulatory energy; CR- controlled respiration; D-BT ${ }_{\text {max }}$ difference between maximal brady-and tachycardia during and following sustained inspiration; LnT- logarithmic transformation (refer to text for details). 


\begin{tabular}{|lccccccccc}
\hline \multicolumn{2}{|c|}{ Table IV - Comparison between VRR parameters of group IIb patients with and without left ventricle hypetrophy (LVH), type II diabetes mellitus (DM), } \\
and overweight (OW)
\end{tabular}

\begin{tabular}{|c|c|c|c|}
\hline \multicolumn{4}{|c|}{ Tabela $\mathbf{V}$ - Diagnostic values of variables analyzed } \\
\hline \multicolumn{2}{|c|}{ Value at sectioning } & Specificity & Sensitivity \\
\hline \multicolumn{4}{|c|}{$\geq 40$ years and $<60$ years } \\
\hline $\mathrm{MCF}(\mathrm{bpm})$ & 67.2 & $51.4 \%(\mathrm{p}<0.001)$ & $33.5 \%(\mathrm{p}<0.001)$ \\
\hline DPNN (ms) & 27.8 & $76.2 \%(\mathrm{p}<0.001)$ & $61.0 \%(\mathrm{p}<0.001)$ \\
\hline TME LnT $\left(\operatorname{Ln~ms} s^{2}\right)$ & 304.9 & $72.6 \%(\mathrm{p}<0.001)$ & $80.7 \%(\mathrm{p}<0.001)$ \\
\hline $\operatorname{HF} \operatorname{LnT}\left(\mathrm{ms}^{2}\right)$ & 121.5 & $74.1 \%(\mathrm{p}<0.001)$ & $67.1 \%(\mathrm{p}<0.001)$ \\
\hline $\mathrm{HFCR} \operatorname{LnT}\left(\mathrm{ms}^{2}\right)$ & 497.7 & $100.0 \%(\mathrm{p}<0.001)$ & $71.4 \%(\mathrm{p}<0.001$ \\
\hline $\mathrm{D}-\mathrm{BT}_{\text {máx }}(\mathrm{bpm})$ & 16.4 & $91.3 \%(\mathrm{p}<0.001)$ & $54.3 \%(\mathrm{p}<0.001)$ \\
\hline \multicolumn{4}{|c|}{$\geq 60$ years and $\leq 80$ years } \\
\hline $\mathrm{MCF}(\mathrm{bpm})$ & 60.7 & $60.1 \%(\mathrm{p}<0.001)$ & $18.3 \%(\mathrm{p}<0.05)$ \\
\hline DPNN (ms) & 18.1 & $65.0 \%(\mathrm{p}<0.001)$ & $53.8 \%(\mathrm{p}<0.001)$ \\
\hline TME LnT (Ln ms²) & 102.5 & $48.2 \%(\mathrm{p}<0.001)$ & $61.6 \%(\mathrm{p}<0.001)$ \\
\hline FH LnT $\left.(\operatorname{Ln~ms})^{2}\right)$ & 44.7 & $54.6 \%(\mathrm{p}<0.001)$ & $62.3 \%(\mathrm{p}<0.001)$ \\
\hline FHCR LnT $\left(\mathrm{ms}^{2}\right)$ & 141.2 & $65.0 \%(\mathrm{p}<0.001)$ & $75.0 \%(\mathrm{p}<0.001)$ \\
\hline${\mathrm{D}-\mathrm{BT}_{\text {max }}}(\mathrm{bpm})$ & 15.9 & $58.7 \%(\mathrm{p}<0.001)$ & $56.3 \%(\mathrm{p}<0.001)$ \\
\hline
\end{tabular}

respiration $(\mathrm{p}<0.001)$. Values of $72.6 \%$ specificity $(p<0.001)$ were found for total modulation energy.

Sensitivity was $67.1 \%$ at high frequency $(\mathrm{p}<0.001)$, $71.4 \%$ at high frequency during controlled respiration $(\mathrm{p}=0.001)$, and $80.7 \%$ for total modulation energy $(\mathrm{p}<0.001)$ in the frequency domain.

Variable values at sectioning in the time domain were $76.2 \%$ specificity for $\mathrm{SDNN}(\mathrm{p}<0.001)$ and $91.3 \%$ for D-BT ${ }_{\text {max }}$ $(\mathrm{p}<0.001)$. Sensitivities had values of $61.0 \%$ for SDNN $(\mathrm{p}<0.001)$ and $54.4 \%$ for $\mathrm{D}-\mathrm{BT} \mathrm{T}_{\max }(\mathrm{p}<0.001)$.

\section{Discussion}

Initial studies on the behavior of the variability of heart rate in systemic arterial hypertension were performed using techniques that analyzed reflex control of heart rate mediated by baroreceptors. Bristow et $\mathrm{al}^{29}$ and Gribbin et al ${ }^{30}$ showed that the reduction in heart rate consequent to baroreceptor activation evoked by increased arterial pressure was significantly less conspicuous in hypertensive individuals. Manci et al ${ }^{31}$ verified that reflex tachycardia caused by a lowered arterial pressure consequent to deactivation of baroreceptors was significantly smaller in hypertensive subjects. These findings demonstrate the close relation between mechanisms controlling arterial pressure and the variability of heart rate, which are impaired in systemic arterial hypertension.

In the frequency domain, the power spectrum band representing modulation energy of the vagosympathetic system (or total modulation energy) showed significantly lower values in group IIa compared with values in group Ia (Table I). This demonstrates that in hypertensive individuals of this age group variability in heart rate is significantly blunted. On the other hand, in agreement with Aono et $\mathrm{al}^{32}$, we verified that values of total modulation energy were not different between groups Ib and IIb, verifying that in group IIa-autonomic modulation of the heart was impaired by systemic arterial hypertension, but in group IIb, the reduced modulation caused by aging was not worsened by hypertension. This is reinforced by the analysis of the predominantly vagal modulation. Thus, comparing groups I and IIa, both at rest and during controlled respiration, values were larger in group Ia ( $p<0.05)$. However, when values at high frequency and high frequency controlled respiration were analyzed under identical conditions, no significant differences between individuals in groups Ib and IIb were found (Table I).

On analyzing differences between high frequency values observed prior to and during controlled respiration within each group, we observed that the increase in vagal modulation energy was less expressive in group $\mathrm{IIa}, \mathrm{Ib}$ and IIb. This result verifies that in the process of autonomic demodulation of the heart the parasympathetic loop was significantly blunted both by age and by arterial hypertension. It is important to note that in individuals 60 years old and above, the presence of arterial hypertension does not intensify the decrease in modulating energy imposed by aging; this contrasts with effects observed among individuals in group IIa. In the higher age group, increased arterial wall rigidity consequent to aging, which directly decreases pressoreceptor sensitivity, is not aggravated by increased levels of tension. In other conditions, like Parkinson's disease, in which direct lesions of the autonomic nervous system may occur, values of the potency energy spectrum in the aged are significantly smaller than those observed in controls of the same age group ${ }^{7}$. Similarly to that observed in the frequency domain, variables in the time domain also 
underwent alterations. On analyzing the DPNN values of group IIa, we verified that they weresignificantly smaller than those in group Ia ( $p=0.001$, Table I). These differences were not significant between groups $\mathrm{Ib}$ and $\mathrm{IIb}$. Yet, in the time domain, we observed that D-BT ${ }_{\text {max }}$ was significantly smaller in group IIa compared with that in group Ia $(\mathrm{p}=0.03)$, but it was not different in groups $\mathrm{Ib}$ and $\mathrm{IIb}$.

The analysis of the variability in heart rate as a function of the existence of diabetes, LVH, or overweight, we observed that this variability was not aggravated by the presence of these morbid conditions, both in regards to frequency and time (Tables II and IV). This finding differs from some reports in the specialized literature ${ }^{33-35}$. It appears plausible, therefore, that these conditions do not aggravate alterations determined by systemic hypertension properly.

From the etiopathogenetic viewpoint, autonomic dysfunction determined by aging ${ }^{32,36}$ or due to various diseases ${ }^{6,7}$ is related to 2 basic causes: 1 ) alterations in pressoreceptor mediated reflexes and 2) intrinsic alteration of the vagosympathetic system.

In healthy individuals, oscillation of intrathoracic pressure evoked by respiratory movement determines increases and decreases in systolic ejection volume ${ }^{37}$. These variations contribute to a significant extent to modifications in arterial pressure during the respiratory cycle. Variation in intravascular arterial pressure conditioned by respiratory movement is perceived by pressoreceptors that modify, moment by moment, efferent potentials conducted to the vasomotor center by the aortic and carotid depressor nerves. Upon arrival to the center and proper processing, this information travels via vagosympathetic efferent pathways towards the heart and vessels causing respectively, cyclic variation in heart rate (respiratory sinus arrhythmia) and peripheral arterial resistance, counteracting variations in stroke volume and preventing large fluctuations in arterial pressure (Figure 3).

In systemic arterial hypertension, pressoreceptor me-

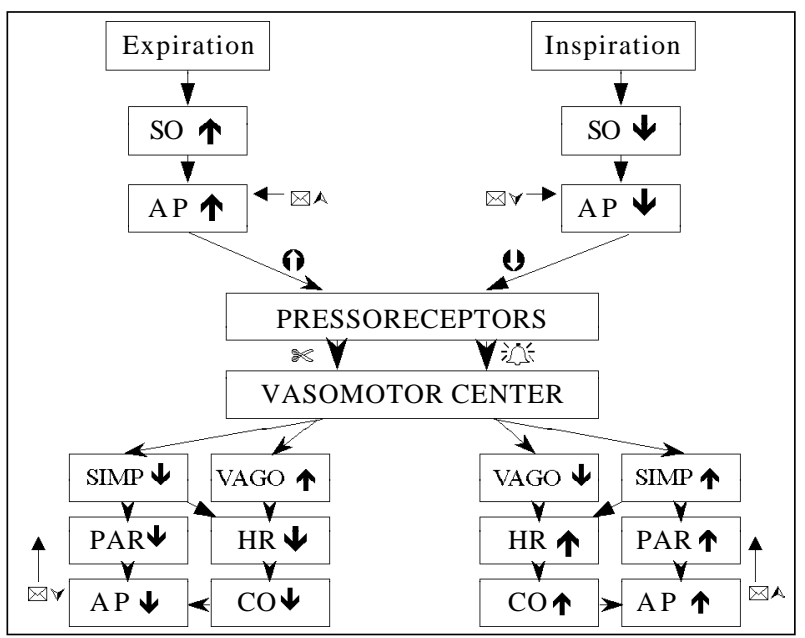

Fig. 3 - Representative scheme of the effect of respiratory phases of inspiration and expiration on the control of heart rate mediated by pressoreceptors. SO, systolic output; AP, arterial pressure; SIMP, sympathetic; PAR, peripheral arterial resistance; $\mathrm{CO}$, cardiac output. diated regulatory mechanisms undergo recycling ${ }^{38}$ and in the same manner as in the aged become less sensitive. Consequently, reflexes show a reduction in gain, that is, a smaller number of action potentials per $\mathrm{mm} \mathrm{Hg}$ of oscillation of arterial pressure in the depressor nerves occurs. The first reflexes act by displacing the threshold of pressoreceptor action to higher arterial pressure levels. The second stop the processing of small arterial pressure variations, attenuating the reflex-modulating capacity of the vagus nerve on heart rate variability, enhancing that of the sympathetic system on arterial vessels.

From the diagnostic viewpoint, by presenting better indexes of discrimination between groups I and II, total modulating energy (TME) and that relative to autonomic modulation including high frequency control of respiration and D-BT ${ }_{\max }$, may constitute an important auxiliary tool for the diagnosis of systemic arterial hypertension. Controlled high frequency respiration allowed the identification of $100 \%$ of the individuals in group Ia and $71.4 \%$ of those in goup IIa; among all variables analyzed, it had the highest diagnostic value for subjects in groups Ib and IIb. Therefore, the presence of alterations in these indexes in patients with high pressure values reinforces a diagnosis of systemic arterial hypertension indicating the existence of an impaired cardiac modulating system.

Thus, we may state that variables that quantify variability in heart rate both in the frequency and time domains, if recorded from patients with systemic arterial hypertension, have significantly lower values compared with the values in healthy subjects. This difference reflects the degree of impairment in baroreflex mediated autonomic cardiac modulation; it can corroborate the diagnosis of systemic arterial hypertension, bringing out the importance of age in the process of autonomic control of the heart.

\section{Appendix}

For the calculation of sensitivity and specificity, an empirical formula having the following steps was developed:

a) construct a histogram of distribution of values of variable $\mathrm{X}$, divided into $\mathrm{N}$ classes with an amplitude interval for each numbered class $\left(\mathrm{C}_{\mathrm{i}}\right)$, for groups I and II (see definition under Methods). Intervals $\mathrm{C}_{\mathrm{i}}$ are defined by lower $\left[(\operatorname{lnf}) C_{i}\right]$ and upper $\left[\operatorname{Sup}\left(C_{i}\right)\right]$, so that variable $\mathrm{X}$ belongs to the interval when $\operatorname{lnf}\left(\mathrm{C}_{\mathrm{i}}\right) \leq \mathrm{X}<\operatorname{Sup}\left(\mathrm{C}_{\mathrm{i}}\right)$. Thus, functions $\mathrm{p}$ $\left(\mathrm{XeC}_{1}\right)$ and $\mathrm{q}\left(\mathrm{XeC}_{1}\right)$, representing the values of the probability of $\mathrm{X}$, associated with each $\mathrm{C}_{\mathrm{i}}$ class of the respective histograms of groups I (p) and II (q), become defined.

b) the probability distribution function of variable $X$ is defined by the cumulative sum of the probabilities of all $N\left(C_{i}\right)$ of the histogram of each group. Thus, functions $\mathrm{p}\left(\mathrm{X} \leq \mathrm{C}_{\mathrm{i}}\right)$ and $\mathrm{Q}\left(\mathrm{X} \leq \mathrm{C}_{\mathrm{i}}\right)$ are functions of the distribution probability of $\mathrm{X}$ to represent the probability that values of $X<\operatorname{Sup}\left(C_{i}\right)$, respectively to groups I (p) and II $(\mathrm{Q}) \cdot \mathrm{p}\left(\mathrm{X} \leq \mathrm{C}_{\mathrm{i}}\right)$ and $\mathrm{Q}\left(\mathrm{X} \leq \mathrm{C}_{\mathrm{i}}\right)$ are equal to 1 for $\mathrm{C}_{\mathrm{N}}$, zero for $\mathrm{C}_{0}$, and grow monotonically.

c) Function $\mathrm{M}\left(\mathrm{C}_{\mathrm{i}}\right)$ is defined as $\left[1-\mathrm{p}\left(\mathrm{X} \leq \mathrm{C}_{\mathrm{i}}\right)\right] \mathrm{Q}\left(\mathrm{X} \leq \mathrm{C}_{\mathrm{i}}\right)$. $\mathrm{M}\left(\mathrm{C}_{\mathrm{i}}\right)$ has values equal to zero at the extremes $\left(\mathrm{C}_{\mathrm{N}}\right.$ and $\left.\mathrm{C}_{0}\right)$ and the maximal value between them $\left(\mathrm{C}_{\max }\right)$. Sensitivity is defined as $\mathrm{Q}\left(\mathrm{X} \leq \mathrm{C}_{\max }\right)$, and specificity as $\left[1-\mathrm{p}\left(\mathrm{X} \leq \mathrm{C}_{\max }\right)\right]$. 


\section{References}

1. Kavachi I, Sparrow D, Vokonas PS, et al. Decrease heart rate variability in men with phobic anxiety (data from the normative aging data). Am J Cardiol 1995; 75 : 882-5.

2. Ajiki K, Murakawa Y, Yanagisawa-Miwa Usui M, et al. Autonomic nervous system activity in idiopatic dilated cardiomiopathy and in hyperttrophic cardiomiopathy. Am J Cardiol 1993; 71: 1316-20.

3. Ryan SM, Goldberger AL, Ruthazer R, et al. Spectral analysis of heart rate dynamics in elderly person with posprandial hypotension. Am J Cardiol 1992; 69: 201-5.

4. Bernardi L, Ricordi L, Lazzari P, et al. Impaired circadian modulation of sympathovagal activity in diabetes: a possible explanation for altered temporal onset of cardiovascular disease. Circulation 1992; 86: 1443-52.

5. Saul JP, Arai Y, Berger RD, et al. Assessement of autonomic regulation in chronic congestive heart failure by heart rate spectral analysis. Am J Cardiol 1988; 61: 1292-9.

6. Barbosa PR, Barbosa FJ, Morais de Sá CA. Influência da idade, sexo e doença coronária sobre a modulação autonômica do coração. Arq Bras Cardiol 1996; 67: 325-9.

7. Barbosa Filho J, Barbosa PRB, Papais-Alvarenga RM, et al. Modulação autonômica cardíaca na doença de Parkinson. Rev Bras Neurol 1999; 35: 75-80.

8. Singh M, Juneja R, Bali HK, et al. Autonomic function in restrictive cardiomyopathy an constrictive pericaditis: a comparison. Am Heart J 1998; 136: 443-8.

9. Huikuri HV, Ylitalo A, Pikkujämsä SM, et al. Heart rate variability in sistemic hypertension. Am J Cardiol 1996; 77: 1073-7.

10. Huikuri HV, Linnaluoto MK, Sppänen T, et al. Circadian rhythim of heart rate variability in survivors of cardiac arrest. Am J Cardiol 1992; 70: 610-5.

11. Dougherty CM, Burr RL. Comparison of heart rate variability in survivors an nonsurvivors of sudden cardiac arrest. Am J Cardiol 1992; 70: 441-8.

12. Hartikainen JE, Malik M, Staunton A, et al. Distiction between arrytmic and nonarrhythmic death after acute myocardial infarction based on heart rate variability, signal-averaged electrocardiagram, ventricular arrhythmia and left ventricular ejection fraction. J Am Coll Cardiol 1996; 28: 296-304.

13. Bigger Jr JT, Fleiss JL, Rolnitzky LM, et al. The ability of several short-time measures of RR variability to predict mortality after after myocardial infarction. Circulation 1993; 88: 927-34.

14. La Rovere MT, Bigger JT, Marcus FI, et al. Baroreflex sensitivity and heart rate variability after myocardial infarction. ATRAMI (Autonnomic Tone and Reflexes After Myocardial Infarction) Investigators. Lancet 1998; 351: 478-84.

15. Kjellgren O, Ip J, Suth K, et al. The role of parasympathetic modulation of the reentrant arrhytmic substrate in the genesis of sustained ventricular tachicardia. Pacing Clin Electrophysiol 1994; 17: 1276-87.

16. Huikuri HV, Mäkikallio TH, Airaksinen J, et al. Power-law relationship of heart rate variability as a predictor of mortality in the elderly. Circulation 1998; 97 : 2031-6.

17. Mäkikallio TH, Koistinen J, Jordaens L, et al. Heart rate dynamics before spontaneous onset of ventricular fibrillattion in patients with healed myocardial infarcts. Am J Cardiol 1999; 83: 880-4.

18. Mäkikallio TM, Höiber S, Köber L, et al. Fractal analysis of heart rate dynamics as a predictor of mortality in patients with depressed left ventricular function after acute myocardial infarction. Am J Cardiol 1999; 83: 836-9.
19. Parati G, Di Rienzo M, Groppelli A, et al. Heart rate and blood pressure variability and their interation in hypertension. In: Malik M, Camm AJ (eds): Heart Rate Variability. Armonk, NY: Futura Publishing Co. Inc., 1995; cap. 35: 467-78.

20. Kosh M, Hausberg M, Barenbrock M, et al. Studies of cardiac sympathovaga balance and large artery distensibility in patients with untreated essential hypertension. J Hum Hypertens 1999; 13: 315-9.

21. Guzzetti S, Piccaluga E, Casati R, et al. Sympathetic predominance inessential hypertension: a study employing spectral analysis of heart rate variability. J Hypertens 1988; 6: 711-7.

22. Piccirillo G, Munizzi MR, Fimognari, et al. Heart rate variability in hipertensive subjects. Int J Cardiol 1996; 53: 291-8.

23. Singh JP, Larson MG, Tsuji $\mathrm{H}$, et al. Reduced heart rate variability and new onse hypertension: insight into patogenesis of hypertension: the Framingham Heart Study. Hypertension 1998; 32: 293-7.

24. Minami J, Kawano Y, Ishimitsu T, et al. Blunted parasympathetic modulation in salt-sensitive patients with essential hypertension evaluation by powerspectral analysis of heart rate variability. J Hypertens 1997; 15: 1997.

25. Presciuttini B, Duorez D, De Buyzere M, et al. How to study sympatho-vagal balance in arterial hypertension and the effect of antihypertensive drugs. Actas Cardiol 1998; 53: 143-52

26. Ylitalo A, Airaksinen J, Sellin L, et al. Effects of combination antihypertensive therapy on baroreflex sensity and heart rate variabilyti in sistemis hypertension. Am J Cardiol 1999; 83: 885-9.

27. Petretta M, Bonaduce D, Marciano F, et al. Effects of 1 year of lisinopril treatmen on cardiac autonomic control in hypertensive patients with left ventricular hypertrophy. Hypertension 1996; 27: 330-8.

28. Barbosa PRB. A signal-averaging system for surface ECG signal analysis. Phys Med Biol 1994; 39: 412.

29. Bristow JD, Honour AJ, Pickering GW, et al. Diminised baroreflex sensitivity in high blood pressure. Circulation 1969; 39: 48-54.

30. Gribbin B, Pickering TG, Sleight $P$, et al. Effect of age and high blood pressure on baroreflex sensitivity in man. Circ Res 1971; 29: 424-31.

31. Mancia G, Ferrari A, Gregori L, et al. Blood pressure variability in man: its relation to age, high blood pressure and baroreflex sensitivity. Clin Sci 1980; 59: 401-3.

32. Aono T, Sato T, Nishinaga M, et al. Power spectral ana lysis of spontaneous blood pressure and heart rate variabiliti in elderly hypertensives. Hypertens Res 1996; 19: 9-16.

33. Heikki VH, Ylitalo A, Pikkujämsä SM, et al. Heart rate variability in systemic hypertension Am J Cardiol 1996; 77: 1073-7.

34. Kohara K, Hanara-Nakamura N, Hiwada K. Left ventricular mass index correlates with heart rate variability. Am J Hypertens 1995; 8: 183-8.

35. Pikkujamsa SM, Huikuri HV, Airaksinen KE, et al. Heart rate variability and baroreflex sensitivity in hypertensive subjects with and without metabolic features of insulin resistance syndrome. Am J Hypertens 1998; 11: 523-31.

36. Barbosa PR, Barbosa Filho J, Morais de Sá CA. Efeito da idade sobre a modulação autonômica do coração. Rev SOCERJ 1995; 3: 79-84.

37. Taylor JA, Eckberg D. Fundamental relations between short-term RR interval and arterial pressure oscillation in humans. Circulation 1996; 93: 1527-32.

38. Michelini LC. Regulação momento a momento da pressão arterial na normotensão e hipertensão. Hipertensão 2000; 3: 90-8. 